\title{
Developmental Guidelines for Good Chairside Teaching - a consensus report from two conferences.
}

(Running title: Good chairside teaching)

(Published on-line 12/11/2014, European Journal of Dental Education, EPub ahead of print doi: 10:1111/eje.12120 Wiley embargo until November 2015)

Jeff Wilson

Clinical Senior Lecturer in Restorative Dentistry

Cardiff University School of Dentistry

College of Biomedical and Life Sciences

Heath Park

Cardiff CF14 4XY

Wales

United Kingdom

John Sweet

Associate Professor

College of Medicine

Swansea University

Swansea

Wales

United Kingdom

Lesley Pugsley

Senior Lecturer in Medical Education

Postgraduate Medical and Dental Education

College of Biomedical and Life Sciences

Cardiff University

Cardiff

Wales

United Kingdom

Key words: chairside, teaching 


\section{Abstract}

Developmental Guidelines for Chairside Teaching are a direct outcome of 10 years of research, originally prompted by feedback from undergraduate dental students who not only thought that the teaching they received was uneven and variable in quality, but also felt strongly that they learned more with educationally trained teachers than those with little or no teacher training.

Workshops embracing the views of teaching colleagues from many other Dental Schools produced a consensus view that developmental guidelines for teachers would provide a valuable resource. A conference to consider all aspects on chairside teaching and learning was convened with delegates invited from all U.K. Dental Schools. This was subsequently followed by a second conference to develop specific guidelines for chairside teaching and learning. The Nominal Group Technique was used in the first chairside teaching conference and Structured Small Expert Groups were used in the second. The overall consensus from these workshops and conferences were:

1) Developmental guidelines for chairside teaching can act as a useful resource for teachers to improve and maintain their standard of chairside teaching

2) Developmental guidelines can be divided into themes of organisational issues and learner and teacher qualities.

3) Guidelines should be "developmental" because they encourage chairside teachers to focus on the next immediate goal to maintain and improve quality and standards.

These developmental guidelines could provide a universal toolkit for improved chairside teaching which would result in a better student learning experience. Set out in this way these guidelines have currency across academic and practical skills levels, different educational systems, philosophies and country boundaries. 


\section{Introduction}

There is a universal need for clinical supervision, teaching and training of dental students whilst they are practising on patients, which is themed "Chairside Teaching". Whether dentistry is considered as a direct specialty or as a sub-speciality of medicine, the majority of chairside teaching in Europe has followed a fairly uncritical apprenticeship tradition. ${ }^{1,2}$ Developmental guidelines for chairside teaching outlined here are the outcome of ten years of research into this theme. It is hoped that conclusions drawn from this experience will prove useful for teachers of dentistry in all European countries (if not world-wide) where there is a groundswell of activity to enlighten chairside teaching from its historical roots, where there is an interest to improve the student learning experience and a willingness to engage with dental teacher presuppositions to improve teaching.

A major finding of the research involving stakeholders in chairside teaching at Cardiff University School of Dentistry, Wales, U.K. was that student groups felt strongly that they

learned more with educationally trained teachers than those with no training. ${ }^{3}$ Additionally, qualified Dental Nurses confirmed the students' view that the teaching they received was uneven and variable in quality. Further consultation with dental tutor colleagues from other Schools produced a consensus view that developmental guidelines for dental chairside teachers could provide a resource they needed in addition to education and training. ${ }^{4}$

This paper outlines how a set of guidelines for good chairside teaching practice was developed from the collective views of dental tutors themselves. The guidelines are first expressed in universal terms that apply to all dental tutors engaged in chairside teaching, followed by additional guidelines identified for those with specific dental tutor roles. These guidelines need to be developmental because good teaching is seen as a continuously evolving process. 


\section{How Chairside Teaching Guidelines were developed}

The then Medical, Dental and Veterinary Subject Centre (MEDEV) of the Institute for Learning and Teaching (now the Higher Education Academy) 'Breaking boundaries' conference in Edinburgh, Scotland in 2005 provided an opportunity to hold a workshop on good practice in chairside teaching with clinical teachers from several dental schools. Reflections from the delegates showed remarkable similarities and concerns about both good and bad teaching practice. This led to a consideration of how chairside teaching could be improved. The consensus from the participants suggested that this research was worthwhile which lead to a MEDEV funded second workshop in London in 2008 to which delegates from all U.K. dental schools were invited. The interest shown by the 18 delegates attending this workshop, plus a general feeling about the importance of the subject led to the first conference on chairside teaching and learning held in 2009 followed by a second conference in June 2011. The guidelines on best practice in chairside teaching have been developed from the data obtained from the consensus views of 106 attendees at the workshops and conferences outlined above. Of the delegates about two thirds were qualified dentists and one third were qualified tutor hygienists, auxiliaries, dental nurses and clinical educationalists.

A series of manuscripts were published on the results obtained from pilot projects carried out between 2005 and 2008 at Cardiff University School of Dentistry under the banner 'Chairside teaching and learning - stakeholders perceptions. ${ }^{3-6}$ The results of these studies showed large variations in the nature, quality and diversity of the chairside teaching being provided within this one school. The researchers, although initially suspecting that the teaching was not as good as it could be, were surprised and alarmed at some of the comments that were forthcoming, especially from the undergraduate Dental Students and Dental Nurses supporting these students at the chairside. In addition to considering how improvements could be made, they wondered whether or not other Dental Schools would produce similar results, using the same research methods to investigate their chairside teaching. 
In summary, previous published research has reported on the views of stakeholders in chairside teaching and also introduced a scenario depicting good chairside teaching practice. ${ }^{3-6}$ It was this material that contributed to an understanding for the need for guidance and the training of dental tutors. The formulation of developmental guidelines involved further approaches of questioning experienced dental teachers actively working in chairside teaching, which produced a consensus of recommendations for good practice. 


\section{Methodology - Qualitative research methods}

The Nominal Group Technique ${ }^{7}$ was used in the First Chairside Teaching Conference. This technique presents a powerful way of allowing the views of all participants to be considered for inclusion in final consensus guidelines. The underlying question, "What should be the guidelines for chairside teaching?" was posed to all participants arranged in small groups. Each individual's proposition was put to a democratic vote that resulted in their ultimate inclusion or exclusion in the list of guidelines.

Structured small expert groups were used in the Second Chairside Teaching Conference. The participants were dental chairside teachers with a range of experience and roles, including dentists, therapists, hygienists and nurses. Their remit was to construct specific chairside tutor developmental guidelines. They were asked to consider a set of draft universal guidelines developed from the first conference and reconcile these with the five dental tutor types that had previously been identified. ${ }^{4}$ 


\section{Results}

Original data obtained using two qualitative research methods from the two chairside teaching conferences is reported here for the first time.

The Developmental Guidelines are set out as statements in seven figures and an accompanying commentary. They should be interpreted in three ways. First, get an overall view of the guidelines by reading the caption outlines for each figure. Second, gain the essential content by reading the statements within the circles in each of the figures. Finally, for a full appreciation, the figures should be interpreted alongside the following commentaries.

\section{Universal Guidelines for Chairside Teaching}

The three essential aspects of chairside teaching are:

- Dental Practice Community (Figure 1)

- $\quad$ Learner Qualities (Figure 2)

- $\quad$ Chairside Teacher Qualities (Figure 3).

Guidelines are stated briefly within the circles with an explanatory caption alongside.

\section{Commentary on Dental Practice Community (Figure 1):}

\section{Clinical Ethos}

The underlying theme of placing patients at the centre of all considerations of the functioning of Dental Practice Community needs to be modelled for incoming students by teachers who lead the dental team, as detailed in Effective Learning and Teaching in Medical, Dental and Veterinary Education ${ }^{8}$ and in the series of papers previously published. ${ }^{3-6}$

\section{Safety}

The ergonomic well-being of teachers, students, nurses, hygienists and therapists should be considered (working environment, posture) as well as that of the patient. Health and Safety guidelines should be followed; there should be an appropriate teacher - student ratio. 


\section{Inter-professional focus}

There should be mutual respect for all members of the dental team and all should develop an understanding of the relationships between team members. It has been shown that a relatively inexperienced dental student learns more from an experienced, trained Dental Nurse supporting them at the chairside than from any clinical supervisor. ${ }^{1,9}$ The value of each member of the dental team and patients should be appreciated, as learning is a distributive phenomenon, not one held exclusively by tutor and student.

The working environment should be non-threatening for the student and the teacher should appreciate individual students' sensitivities. Even the mildest of criticism in front of the patient, dental nurse or other students can be perceived as humiliation by the student and lead to a loss of confidence. If justified, negative feedback should be given on an individual basis in a safe environment where the conversation is unlikely to be overheard. The reason for the negative feedback should be stated and the student given a chance to explain why the situation arose before any severe criticism is delivered. Sarcasm should be avoided and the possibility for a positive learning outcome explored rather than the student becoming distressed and fearful of the next clinical encounter with any particular teacher.

\section{Consistency in teaching}

Teachers should employ the same teaching methodology for all students, avoiding bias. There should be consistency amongst teachers, all should be teaching the same methodology so as to avoid confusion in the minds of the students. Teachers should exercise good time-keeping management and generally act in a professional manner. They should set a good example to the student - teacher as role model - and be inspiring rather than intimidating. A learning contract should exist between teacher and learner, with all involved having input, ownership and regard for the agreed rules and standards. 


\section{Institutional support and recognition}

One of the recurring themes that emerged from the workshops and conferences was the lack of support and recognition for teaching as a pathway for career progression. Delegates were far happier working in an environment where the Head of School was supportive of teaching rather than being obliged to concentrate on research outputs and grant income. The general observation that 'research is everything, teaching counts for little' seems to prevail at most universities whereas the reality is that Dental Schools predominantly receive more income for teaching than they do for research.

\section{Commentary on Learner Qualities (Figure 2)}

Within the safe clinical environment provided, the learner must take responsibility for making the most of the opportunities available. The dental tutor must provide clear learning objectives for the learner and the learner, in turn, must take a positive lead in taking responsibility to achieve those learning objectives. The learner must also take responsibility for having sufficient knowledge about clinical procedures well before they are about to happen and with this to have a clear sense of priorities for all of the outcomes that are achievable. Within a structured portfolio the learner can record aspects of treatment and learning that have occurred. Over the period of clinical training dental students need to be able to self-assess their own actions. This in the wider Higher Education setting has been termed "self-authorship" and is where learners have an understanding and identity that allows them to listen to multiple perspectives, interpret those perspectives in the light of relevant evidence, and make realistic judgements. ${ }^{10}$

\section{Commentary on Chairside Teacher Qualities (Figure 3)}

Dentistry is a practical subject, and learning clinical skills could be better described as an apprenticeship that accompanies an academic education. Despite being deemed competent after phantom head training, many students are very nervous and reticent about performing invasive procedures on patients when they first venture onto clinics. They will often ask for help or guidance when they are performing something for the first time, or stop and seek 
guidance on how to proceed before finishing a procedure. This can be frustrating for the teacher who may become impatient or stressed, especially with a high student-staff ratio and a busy clinic. Care must be taken not to intimidate or humiliate students in this important formative situation.

Teachers should try to be as 'hands-off' as possible and give practical guidance when needed, but appreciate that less confident students may initially need more support than others.

The teacher is the role model, especially in the clinical situation, as well as having to take full responsibility for the patient. However, it is important to take everyone's opinions into consideration, including that of patients, when deciding what the student is capable of achieving and what is likely to be the best outcome for patients under the care of any individual student. Tact and diplomacy is therefore essential when intervening in any clinical episode, even when clinics are busy and the teacher themselves may be stressed.

To summarise, teachers should:

- allow the student to 'set the scene' - what they are attempting to achieve with the patient for any particular clinical episode

- $\quad$ recognise and adapt to learners' needs and levels of competence

- $\quad$ set ground rules so that the student has some idea of how far they should proceed before seeking help or guidance

- $\quad$ link teaching to defined course competencies.

- be explicit in what students are told

- $\quad$ give plenty of opportunity for questions

- $\quad$ ensure that the student has understood what has been said

- $\quad$ try not to intervene in clinical procedures unless the patient is 'at risk'

- demonstrate respect for the student at their stage of development

- $\quad$ stimulate critical thinking on the part of the student

- understand student expectations and anxieties

- $\quad$ give constructive feedback wherever possible 
Students are not telepathic. Some will need very basic instruction and guidance initially as they develop their confidence whilst others seem to adapt naturally to the clinical environment. This is perfectly normal and the good teacher must make allowance for the different learning styles and anxieties amongst students.

Prepare to discuss rather than be didactic; be flexible in approach; stimulate critical thinking; guide rather than dominate and always have evidence to reinforce assertions. Challenge students when they are perceived to be ready but be perceptive about their responses, which may indicate they were not as competent as thought. A non-confrontational, supportive approach is generally more productive.

\section{Briefing and Feedback}

It is important before each clinical episode to ascertain a student's preparedness and competence for the procedure they are about to undertake. Briefing sessions, whether individual or collective, give an opportunity for students to ask questions, more for their own reassurance rather than because they don't know anything about the procedure they are attempting to perform. Unfortunately, this can sometimes appear as ignorance and provoke a negative response that would not inspire confidence, especially in front of patients or peers. Junior students especially benefit from individual briefings, as they progress to become more experienced then group briefings become less threatening and more informative for all. They give the opportunity to learn from other members of the group, for other members of the group to be supportive of the weaker members, and for the teacher to intervene in a positive manner if any concerns emerge. They also give the teacher the opportunity to identify unprepared, weak or failing students who may need help before being allowed to practice on patients. This should be done individually if possible.

The ability to be able to learn from clinical experiences and use them to improve future practice is an essential skill of a clinician. Teachers can stimulate this process in the practice community by helping to create a non-judgemental atmosphere, with opportunities for verbal briefing and debriefing, and textual recording of eventual circumstances and feelings as a narrative. 
Feedback is an essential and powerful learning tool and, as with briefing sessions, can be done on an individual or group basis. Feedback sessions should emphasise the positive outcomes whilst giving the opportunity to analyse what did not go quite as well as it should have and to identify areas for improvement. It is important to remember the patient in the feedback process as they can often give clues about individual students' interpersonal skills and ability to manage patients effectively.

Group feedback sessions in which members of the group are able to question each other can provide suggestions and helpful advice for future clinical episodes or, on occasion, fill gaps in knowledge in a non-threatening environment. They also give the teacher the opportunity for correcting misunderstandings that would otherwise be disseminated by the group.

A clinical logbook in which the student can record all procedures that were carried out together with their own personal reflection on the outcome of the clinical episode together with comments and, perhaps, a grading of their performance is a powerful educational tool. It also provides a portfolio for assessing competence and developing reflective practice. A portfolio of achievement is a source of evidence when assessing individual students' competence and can be useful evidence should the need to deal with failing students arise. These portfolios can be combined into one e-portfolio which can be a portable tool documenting progress throughout training, forming part of a curriculum vitae.

Reflective practice is now desirable for all dentists and in some European countries is mandated by their regulating professional bodies (e.g. The General Dental Council in the United Kingdom). ${ }^{11}$ Reflective practice should be an integral part of dental student training. The portfolio is a useful tool in which the student can reflect on their outcomes, both academic and clinical, and carry forward with them for their future professional careers.

\section{Assessment}

Assessment is essential in clinical disciplines for protection of the patient and is mandatory in dental undergraduate training. This is not just trying to prevent the occasional adverse clinical episode that takes place during every clinician's training, but also is concerned with ensuring that a student only undertakes clinical procedures that they have been trained to 
do, feel confident to undertake and are deemed competent to perform at any given stage of their career.

Teachers should follow their educational institution's standard protocols for assessment and should embrace them fully and honestly, giving evidence-based feedback. Students crave feedback, not just because they want to pass their various assessments but they genuinely need to know how they are progressing, especially when it comes to the clinical management of patients.

Best practice for assessment is self-assessment after reflective practice. Students should be encouraged to self-assess and be guided where necessary to reach the correct conclusions. Grading, if practised, should honestly reflect the student's performance and the student given the opportunity to challenge the grade if it is felt unfair. This creates an opportunity for rational discussion between clinicians that can only have a beneficial outcome, even if the assessment grade was below average. The teacher who consistently gives all students a satisfactory or above average grade achieves nothing in terms of learning as students are then left wondering if they are actually improving as they progress through the course. The worst possible outcome would be to inspire overconfidence in less experienced students. Results from surveys have shown that the majority of students tend to be hypercritical of their own performance giving themselves poorer grades than their actual performance merits. ${ }^{4}$

\section{Scholarship}

It is essential for teachers to maintain their teaching skills and to keep up-to-date with educational theory. They must also be able to link educational theory to teaching practice. It is only by understanding effective educational techniques that one will be able to apply them in the educational situation. To be a good teacher does not mean the ability to impart knowledge and be well liked as a personality by your students. It is the ability to stimulate and facilitate learning in students that distinguishes the good clinical teacher from the supervisor. Didactic teaching does have its place, especially in dentistry, where clinical techniques need to be learned but the ability to stimulate critical thinking in students is the 
ultimate goal. ${ }^{12}$ It would therefore be advantageous if some continuing professional development in educational practice was an essential part of all clinical teachers' training. It would also be advantageous to have a mentor scheme for supporting relatively inexperienced teachers, especially for those teaching episodes that do not go as well as planned and leave the teacher adversely reflecting on their teaching skills.

Peer assessment of teaching is one of the best ways for teachers to develop their teaching qualities, as long as it is performed in a non-threatening environment. A general feeling amongst tutors at the chairside conferences was that there is great resistance to the introduction of peer review of teaching in the clinical setting, but once it is carried out routinely it becomes an accepted and integral tool in teacher training.

\section{Innovative teaching}

Students respond well to innovative teaching techniques employed by innovative teachers, especially in subjects they can see as relevant. ${ }^{13}$ Most appreciate teachers who allow them to learn for themselves whilst being ready to help with difficult problems. For example interactive lectures as opposed to didactic lectures can stimulate and provoke participants rather than having part of the audience becoming bored with the topic after a relatively short time. Small group working within larger groups, with the teacher as facilitator, work extremely well if the students are prepared for a topic in advance. Role-play sessions can work well, especially with clinical scenarios and surrogate patients.

\section{Teacher training}

The view that "good teaching can be learned" is now widely supported, from learning specific good teaching techniques ${ }^{14}$ to recognising necessary values that good teaching expresses. ${ }^{15}$ The feedback obtained from focus groups with other stakeholders, i.e. Dental Students and Dental Nurses also supported this assertion because a common thread was that the student could easily identify the trained teacher as a better teacher and learned more from them. This applies to all teachers whether full or part time, whether experienced or inexperienced and whether considered experts or generalists in their chosen clinical discipline. 
Most universities now require a postgraduate teaching qualification of some kind (certificate, diploma or degree) before employing teachers, and some form of in-house, teacher training induction is required before becoming an independent teacher.

Interpersonal skills can be learned, developed and improved by all, and it has been shown that individuals do not realise how poor they are at interacting with others until they undertake some communication skills training. ${ }^{16}$ Even a good communicator can improve their interpersonal skills, and those who are poor communicators benefit enormously by this type of learning. It is essential for any healthcare professional to have good interpersonal skills, and equally essential for teachers to have these skills. Therefore communication skills training is an essential part of teacher training.

\section{Developmental Guidelines for Teachers with Specific Roles}

For dental teachers with specific roles, specific guidelines were developed by the participants at the Second Chairside Teaching Conference. They identified four specific and vital teacher roles of increasing complexity and responsibility in the clinical organisation:

- $\quad$ General Dental Practitioner teacher (Figure 4)

- $\quad$ Teacher-Trained Academic (Figure 5)

- $\quad$ Senior Academic or Subject Specialist (Figure 6)

- $\quad$ Academic Lead or Departmental Head (Figure 7).

Again, for each figure, the suggested guidelines are stated briefly in the circles with an explanatory caption alongside.

\section{Commentary on Specific Role Guidelines}

General Dental Practitioners (Figure 4) who undertake clinical teaching on a part time basis, most of whom had some postgraduate educational training. The guidelines for them are intended to produce a steadying and stabilising influence on the clinical learning and teaching environment. These teachers should be committed to furthering their own educational learning and development. 
Teacher Trained Academics (Figure 5) who could take on more responsibility for teaching and supporting other teachers in addition to students.

Senior Academics and Subject Specialists guidelines (Figure 6) not only involve the primary responsibility of setting clear learning objectives and outcomes for delivery but pinpoint key elements in the educational process to ensure the effectiveness of teaching.

Academic Leads or Departmental Heads (Figure 7) for teaching articulate guidelines that are key to institutional success in chairside teaching and have rarely been articulated before. Senior academic leads who run chairside teaching clinics will need qualifications and extensive management skills to support continuing education of their staff. They will need to encourage lines of communication and work vertically with colleagues of varying seniority as well as working horizontally as an inter-professional team.

Defending teaching against other institutional pressures is paramount. Critical for clinical training success is to find the right balance for teaching hands-on and teaching in the class room or simulation, and to be constantly open to curricular change. Academic Leads must ensure that the feedback processes instituted at all levels are acknowledged and worked with for suitable learning and change. 


\section{Discussion}

An interesting outcome from these workshops and conferences on chairside teaching was just how much agreement there generally was between dental chairside teachers on the important issues at stake. Our previously reported data showed that there was a cohort of dental teachers who were untrained. ${ }^{4}$ This was not found to be the current experience of those participants at the Second Chairside Conference. They reported that a majority of practitioners involved in chairside teaching in their Schools already possessed some form of educational training delivered by Postgraduate Institutes. They were aware of teacher-trained academics and Senior Academic Subject Specialists in their institutions and could report on educational roles for Academic Lead or Departmental Head. This appears to be a pleasing improvement on the previously reported situation, where there appeared to be very little interest taken in teaching by lead academic figures. It is hoped that the specific role guidelines will be a stimulus for those designated to take up the challenge of staff development and agenda for educational change within their institutions.

The different dental teacher roles are based on the perceptions of a range of dental teachers active in chairside teaching who participated in the workshops and conferences. These will be certain to be augmented as clinical dental training progresses. We hopefully foresee much greater appreciation of inter-professional roles in the future. 


\section{Conclusion}

This whole research approach has been "bottom-up" taking ideas from those experienced and engaged in chairside teaching. The guidelines are seen as an incentive for dental tutors to initiate and maintain their personal education and contribute to the educational environment in their institution in a process of continual improvement. This contrasts with the Guidelines for Dental Educators set out by the Committee of U.K. Postgraduate Dental Deans and Directors (COPDEND) ${ }^{17}$ which was derived from a more "top-down" approach, with an ambition to be a first stage in defining agreed standards for dental educators, and is thus more of a management tool. It is hoped that the one will complement the other. The aim is that the guidelines set out here have an accessibility and directness that will inspire dental tutors wherever they are based. 
Acknowledgements.

The authors would like to thank following:

the teachers from a majority of U.K. Dental Schools and Postgraduate Deaneries who participated in the conferences and workshops leading to the development of these guidelines; the undergraduate Dental Students and Dental Nurses who contributed to the research via the focus groups; the Dental Illustration staff at Cardiff University, especially Christie Conlon; and finally we would like to thank the staff of what formerly was MEDEV (Higher Education Academy), not only for encouraging and supporting this research with multiple grants, but also for being so helpful with organising the conferences and workshops. 


\section{References}

1. Rouge J. Apprentissage de la methodologie diagnostique. J Odontol Conserv 1987; 5:51-53.

2. Aprendizaje e investigacion en programas de 'odontologia institucional'. Cent Estud Recur Odontol Nino 1980; 5:23-26.

3. Sweet J, Pugsley L, Wilson J. Stakeholder perceptions of dental chairside teaching and learning. Br Dent J 2008; 205:499-503.

4. Sweet J, Wilson J, Pugsley L. Chairside teaching and the perceptions of dental teachers in the UK. Br Dent J 2008; 205:565-569.

5. Sweet J, Wilson J, Pugsley L et al. Tools to share good chairside teaching practice. Br Dent J 2008; 205: 603-606.

6. Sweet J, Wilson J, Pugsley L. Educational innovations for dentistry. Br Dent J 2009; 206: 29-34.

7. Delp P, Thesen A, Motiwalla J and Seshardi N. Systems tools for project planning. Bloomington, Indiana: International Development Institute. 1977.

8. Sweet J, Huttly S, Taylor I (eds). Effective Learning and teaching in Medical, Dental and Veterinary Education. London: Kogan Page, 2003.

9. Lawton FE. What can be done to correct deficiencies in the undergraduate dental course? Int Dent J 1976; 26:67-72.

10 Baxter Magolda M B, King P M. Learning Partnerships: Theory and Models of Practice to Educate for Self-Authorship. Sterling, Virginia: Stylus. 2004.

11 Preparing for practice: Dental team learning outcomes for registration. London: General Dental Council, 2011.

http://www.gdc-

uk.org/newsandpublications/publications/publications/GDC\%20Learning\%200utcome s.pdf

12. Behar-Horenstein L S, Dolan TA, Courts FJ, Mitchell G S. Cultivating critical thinking in the clinical learning environment. J Dent Educ 2000; 64:610-615.

13 Obrez A, Briggs C, Buckman J, Goldstein L, Lamb C, Knight W G. Teaching clinically relevant dental anatomy in the dental curriculum: description and assessment of an innovative module. J Dent Educ 2011; 75:797-804.

14 Lemov D. Teach Like a Champion: 49 Techniques That Put Students on the Path to College. San Francisco: Jossey-Bass, Wiley. 2010.

15 Staff and Educational Development Association. Further Guidance on the SEDA Values. http://www.seda.ac.uk/professional-development.html?p=2_1_1

16 Hargie O D W (ed). The Handbook of Communication Skills. 2nd ed. London: Routledge. 1997 
17 Bullock A, Firmstone V. COPDEND Guidelines for Dental Educators: a framework for developing standards for educators of the dental team, London: Royal College of Surgeons of England, 2008.

http://www.rcseng.ac.uk/fds/documents/COPDEND\%20Educators\%20Dental\%20Edu cators\%20Guidelines.pdf 
Figure 1

\section{Universal Guidelines for Chairside Teaching 1}

Starts with the provision of a Dental Practice Community environment that students can feel comfortable to join and contribute. It features a ready working atmosphere that students can imbibe and systems of support for them that can ensure that they will be able to put the patient first in their dealings with them.

Figure 2

\section{Universal Guidelines for Chairside Teaching 2}

Continues with an emphasis on Learner Qualities. It is essential that students are expected to follow high standards of behaviour from the beginning of their clinical career and take responsibility for their learning. The style of teaching and support must move away from straight instruction to reduce dependancy and allow this to happen.

Figure 3

\section{Universal Guidelines for Chairside Teaching 3}

Outlines the professional nature of being a chairside teacher. This necessitates being trained in educational practice and treating each student "As I would like to be... if I were that student". It entails modelling reflective practice that learns from the past and delivers advice for future actions. The teacher has the capacity to recognise learning opportunities and use them.
Dental Practice Community

Clinical Ethos - putting the patient first

Safety - adequate staff/student ratios, materials and equipment used ergonomically

Interprofessional support

Clinical Guidlines for procedures to gain consistency in teaching
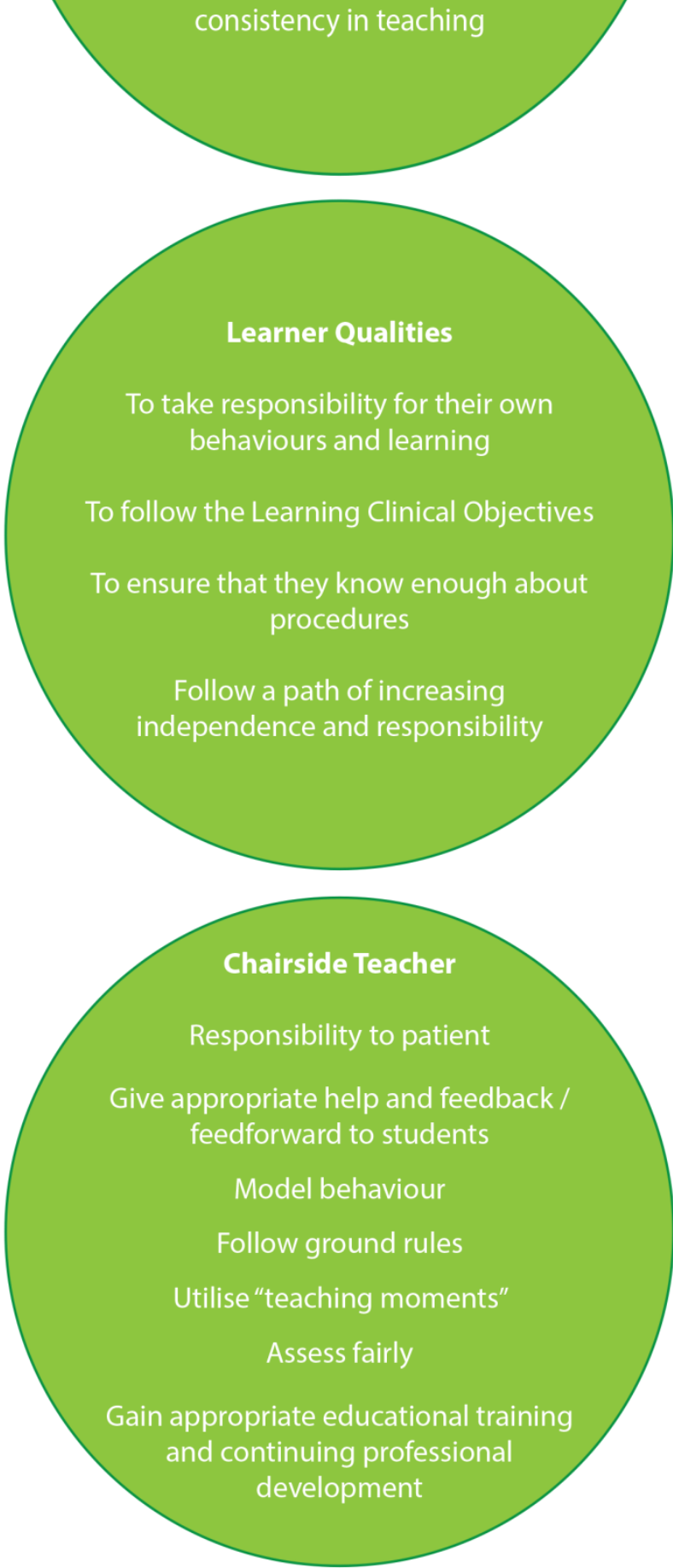
Figure 4

\section{Guidelines for Chairside Teachers with Specific Roles 1}

Some baseline educational training is now necessary to become a chairside teacher.

Professionalism of both clinical work and the educational process will provide more reliable and appropriate support for learners who are themselves becoming more self reliant.

Figure 5

\section{Guidelines for Chairside Teachers with Specific Roles 2}

Teacher trained academics are being guided here to go ahead and utilise their training and skills tempered by experience. The ethical and pastoral dimension of good teaching practice is emphasised. The educational development of other teachers is a natural outcome of being educationally trained and own professional development.

\section{Figure 6}

\section{Guidelines for Chairside Teachers with Specific Roles 3}

Senior academics and subject specialists are seen as contributing strongly to the overall chairside curriculum and its successful interprofessional implementation. This is to be achieved by their direct engagement in teaching and processes of giving feedback including appraisal.

\section{Dental Practitioners}

1. Consistency at foundation core level

2. Holistic approach to the learning and teaching experience

3. Ability to apply appropriate agreed assessments to students

4. To encourage responsibility for their own learning and professional development

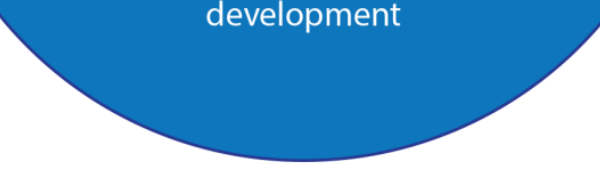

Teacher trained academics

1. Dichotomy of teaching teachers and students - innovative teaching and

assessment alongside tried and tested practices

2. Wellbeing of students and teachers

3. Lead by professional example

4. Support and mentor new and existing teachers

5. Development of teachers by contributing to courses
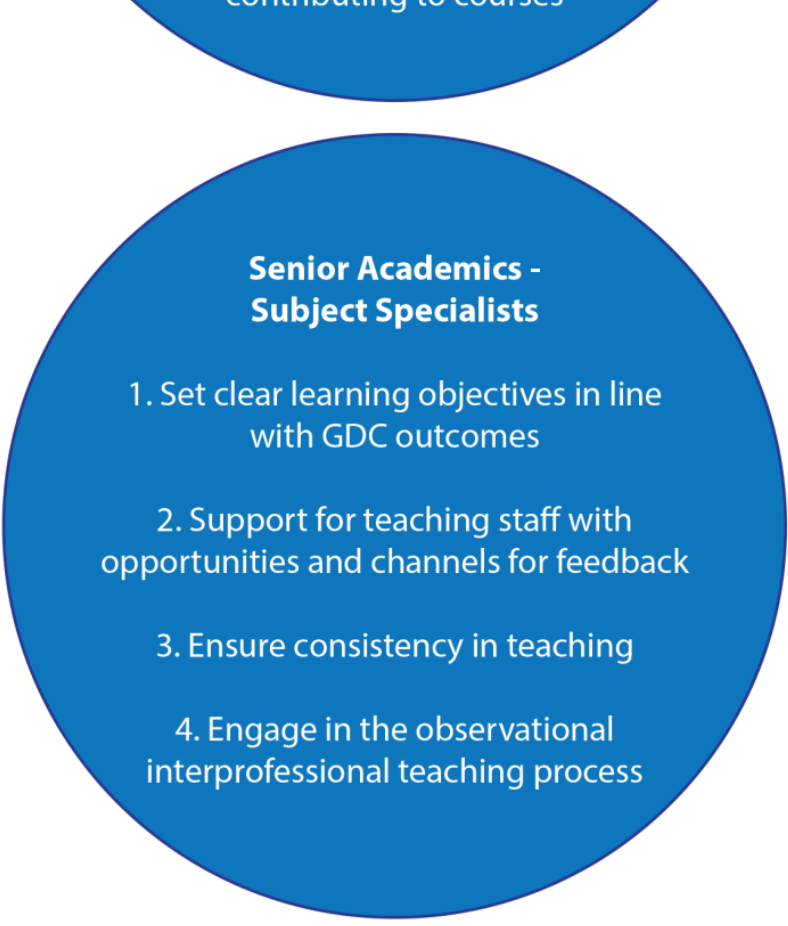
Figure 7

\section{Guidelines for Chairside Teachers with Specific Roles 4}

This Guideline sets out how a Lead Academic can get a grip on educational issues to make a significant difference to the Clinical Teaching Environment. Opportunities for later years to model good practice and mentor earlier years should be encouraged as vertical integration and topics and support for years integrated horizontally.
Academic Lead - Departmental Head

1. Set the 'bar' requirements for qualifications and training continued through appraisal

2. Funding and support for teaching

3. Vertical and horizontal integration

4. Facilitate formalised learning with clinical practice

5. Curriculum dynamic open to innovation and facilitate changes

6. Close the loop on feedback by responding to it appropriately 